\author{
Yi-Ling Hsieh ${ }^{1}$ \\ Tse-Hsien Chen ${ }^{1}$ \\ Ching-Piao Liu $^{2}$ \\ Chuen-Ying Liu ${ }^{1}$ \\ ${ }^{1}$ Department of Chemistry, \\ National Taiwan University, \\ Taipei, Taiwan \\ ${ }^{2}$ Department of Biochemical \\ Science and Technology, \\ National Taiwan University, \\ Taipei, Taiwan
}

\section{Titanium dioxide nanoparticles-coated column for capillary electrochromatographic separation of oligopeptides}

\begin{abstract}
A novel column made through the condensation reaction of $\mathrm{TiO}_{2}$ nanoparticles $\left(\mathrm{TiO}_{2} \mathrm{NPs}\right)$ with silanol groups of the fused-silica capillary is described. EOF measurements under various buffer constitutions were used to monitor the completion of reactions. The results indicated that the EOF was dependent on the interactions between buffers and the bonded $\mathrm{TiO}_{2} \mathrm{NPs}$. With formate/Tris buffer, EOF reversal at $\mathrm{pH}$ below 5 and cathodic EOF at $\mathrm{pH}$ above 5 were indicated. The $\mathrm{pl}$ of the bonded $\mathrm{TiO}_{2} \mathrm{NPs}$ was found at $\sim$ ph 5 . Only cathodic EOF was illustrated by substituting the mobile phase with either glutamate or phosphate buffer. It was elucidated that both glutamate and phosphate buffer yield a negative charge layer on the surface of $\mathrm{TiO}_{2} \mathrm{NPs}$ attributable to the formation of a titanium complex. The CEC performance of the column was tested with angiotensin-type oligopeptides. Some parameters that would affect the retention behavior were investigated. The interactions between the bonded phases and the analytes were explicated by epitomized acid-base functional groups of the oligopepetides and the speciation of the surface oxide in different $\mathrm{pH}$ ranges. The average separation efficiencies of $3.1 \times 10^{4}$ plates $/ \mathrm{m}$ is readily achieved with a column of $70 \mathrm{~cm}(50 \mathrm{~cm}) \times 50 \mu \mathrm{m}$ ID under an applied voltage of $15 \mathrm{kV}$, phosphate buffer ( $\mathrm{pH} 6.0,40 \mathrm{~mm})$, and UV detection at $214 \mathrm{~nm}$.
\end{abstract}

Keywords: Capillary electrochromatography / Condensation / Oligopeptides / Sol-gel / Stationary phase / Titanium dioxide nanoparticle

\section{Introduction}

Titanium dioxide has recently been drawing a great interest in the field of HPLC, due to the fact that it surpasses silica with regard to its hydrolytic stability. The surface of titanium dioxide was widely modified with octadecylsilane (ODS) for the comparison with traditional RP system [1-5]. In addition, Pinkse et al. [6] newly reported selected isolation at the femtomole level of phosphopeptides from proteolytic digests using 2-DnanoLC-ESI-MS/MS and titanium oxide precolumns. A titanium dioxide precolumn has also been developed for selective adsorption of phosphopeptides by Sano and Nakamura [7]. However, little attention has been paid to the applicability of titanium dioxide in CE and CEC. A preliminary work concerning titanium dioxide coating

Correspondence: Professor Chuen-Ying Liu, Department of Chemistry, National Taiwan University, 1, Sec. 4, Roosevelt Road, Taipei 10617, Taiwan

E-mail: cyliu@ntu.edu.tw

Fax: $+886-2-23638543$

Abbreviations: Ang-I, human angiotensin I acetate salt; Ang-II, human angiotensin II acetate salt; Ang-ST, $\left[\mathrm{Sar}^{1}, \mathrm{Thr}^{8}\right]$ angiotensin II acetate salt; $\mathrm{TiO}_{2} \mathbf{~ N P s}, \mathrm{TiO}_{2}$ nanoparticles; TIP, titanium (IV) isopropoxide produced by the sol-gel method for CE separation of proteins was notified by Tsai et al. [8]. Fujimoto [9] prepared a titanium dioxide column by introducing a solution of titanium peroxo complex into the fused-silica capillary, followed by heating at an elevated temperature $\left(450^{\circ} \mathrm{C}\right)$. He ascertained that satisfactory separation of four inorganic ions could be achieved, while an ODSmodified column was indispensable for the separation of carbohydrates and proteins.

The chemical and physical properties of a compound in nanosize are uniquely distinct from that in bulk material. Interaction phases in CEC normally consist of packed particles [10-13], monolithic beds [14-17], or bonded phases [18-24]. Recently, applications of nanoparticles as stationary phases of CEC have drawn attention. Gold particles in running buffer adsorbed to the capillary wall were consumed as interaction phases in open-tubular CEC [25]. The use of alkylthio gold nanoparticles in opentubular CEC has been reported [26, 27]. Viberg et al. [28] employed polymeric nanoparticles as pseudostationary phases in CEC/ESI-MS for the separation of three amines. This technique shows promising features for analysis of analytes in complex matrixes, though it is not fully optimized for the separation. 
As a rule, peptides and proteins are separated by HPLC under gradient conditions. The substantial selection of sorbents for HPLC results from the extensively investigated separation mechanisms for peptides and proteins on these columns. As opposed to HPLC, CEC shows potential for the peptide separation attributable to its capabilities of separating charged and neutral molecules in a single run [29-32]. Yet, the stationary phases available for this new technique are under sprout. As long as more stationary phases are presented, CEC will be able to continue its rapid growth.

The aim of this work is to exploit $\mathrm{TiO}_{2}$ nanoparticles $\left(\mathrm{TiO}_{2} \mathrm{NPs}\right)$ as the stationary phases of CEC. Based upon our experience, the open-tubular format is conceptually a simple column design in terms of CEC [18-23]. Nonetheless, a stable surface-bonded coating is essential to provide efficient chromatographic separations and reliable EOF. The column preparation by sol-gel approach is a proficient means since it enables a direct stationary phase bonding to capillary walls [33, 34]. Oliva et al. [35] studied the adsorption behavior of HSA onto colloidal $\mathrm{TiO}_{2}$ particles. Therefore, the possibilities to prepare an open-tubular CEC column by condensation reaction from the $\mathrm{TiO}_{2} \mathrm{NPs}$ directly with the silanol groups on the surface of the inner wall of a fused-silica capillary are described. To characterize the prepared column further, angiotensin-type oligopeptides are employed as the model compounds to evaluate the separation performance.

\section{Materials and methods}

\subsection{Apparatus}

All experiments were carried out in a laboratory-built unit. It consists of a $\pm 30 \mathrm{kV}$ high-voltage power supply (Gamma High Voltage Research, Ormond Beach, FL, USA) and a UV-visible detector (Model L-4200, Hitachi, Japan). Electrochromatograms were recorded and processed with a Peak-ABC Chromatography Workstation Ver. 2.11 (JiTeng Trading, Singapore) running on Window XP operating system. Fused-silica capillaries with $50 \mu \mathrm{m}$ ID and $375 \mu \mathrm{m}$ OD were purchased from Polymicro Technologies (Phoenix, AZ, USA).

\subsection{Reagents and chemicals}

Most chemicals were of analytical reagent grade from Merck (Darmstadt, Germany). Purified water (18 $\mathrm{m} \Omega$ $\times \mathrm{cm}$ ) from a Milli-Q water purification system (Millipore, Bedford, MA, USA) was used to prepare all solutions. Human angiotensin I acetate salt (Ang-I, p/7.91), hu- man angiotensin II acetate salt (Ang-II, p/7.76), and [Sar ${ }^{1}, \mathrm{Thr}^{8}$ ] angiotensin II acetate salt (Ang-ST, p/ 9.85) were obtained from Sigma (St. Louis, MO, USA). Perchloric acid, benzyl alcohol, phosphoric acid, sodium phosphate (monobasic, dibasic, and tribasic) and Tris (Merck), formic acid, L-glutamic acid, 1-propanol, PEG (average $M_{r}=8000$ ) (PEG 8000), sodium hydroxide and hydrochloric acid (Acros, Geel, Belgium), and titanium (IV) isopropoxide (TIP) (Fluka, Buchs, Switzerland) were purchased from the indicated sources.

Stock solutions of the oligopeptides $(5 \mathrm{mg} / \mathrm{mL})$ were prepared in pure water and diluted appropriately prior to use. All solvents and solutions for CEC analysis were filtered through a $0.45 \mu \mathrm{m}$ PTFE (Millipore) or cellulose acetate membrane (Whatman).

\subsection{Sol-gel procedure}

$\mathrm{TiO}_{2}$ colloidal suspension was prepared by dropwise addition of $0.74 \mathrm{~mL}$ of $10 \%$ TIP in 1-propanol to perchloric acid solution (50 mL, $\mathrm{pH} 1.5)$ which was precooled at $4^{\circ} \mathrm{C}$, with vigorous stirring in an ice bath for $1 \mathrm{~h}$. The resultant mixture was further reacted at $50^{\circ} \mathrm{C}$ with stirring for $7 \mathrm{~h}$. Freshly prepared colloidal suspension was used in all the experiments.

Transmission electron microscopy was carried out by applying $10 \mu \mathrm{L}$ of the colloidal sample to the carboncoated copper grid. Particle sizes were determined from the photographs. Absorption spectra were recorded with a Hitachi U3200 spectrophotometer.

\subsection{Column preparation}

Fused-silica capillaries were first flushed with $1 \mathrm{M} \mathrm{NaOH}$ (30 min), then pure water (15 min), $1 \mathrm{~m} \mathrm{HCl}$ (30 min), and pure water $(15 \mathrm{~min})$. Before introducing the sol-gel $\mathrm{TiO}_{2} \mathrm{NPs}$, the capillaries were rinsed with methanol ( $5 \mathrm{~min}$ ) and then dried in a GC oven at $110^{\circ} \mathrm{C}$ for $1 \mathrm{~h}$ under a nitrogen flow of $250 \mathrm{~kg} / \mathrm{m} \times \mathrm{s}^{2}$.

PEG 8000 (16 mg) was added dropwise to the $\mathrm{TiO}_{2}$ colloidal suspension $(100 \mathrm{~mL})$ with stirring to get a homogeneous solution, then concentrated under vacuum at $50^{\circ} \mathrm{C}$ to remove excess solvent (1-propanol). The resultant material (around $1 \mathrm{~mL}$ ) was introduced into the capillary column under a nitrogen flow of $100 \mathrm{~kg} / \mathrm{m} \times \mathrm{s}^{2}$ for $10 \mathrm{~min}$, then plugged with GC septa and reacted at $150^{\circ} \mathrm{C}$ for $24 \mathrm{~h}$. The resulting column was flushed successively with methanol, $0.1 \mathrm{M} \mathrm{NaOH}$ and pure water for $10 \mathrm{~min}$ to remove unreacted material. 


\subsection{Capillary electrochromatographic conditions}

Before analysis, the coated capillaries were preconditioned with the running buffer. They were rinsed with methanol, pure water, and buffer between runs at 1 or 2 min intervals. The samples were injected electrokinetically. EOF was measured with benzyl alcohol. The samples were detected by UV light absorption measurement at $214 \mathrm{~nm}$.

\section{Results and discussion}

\subsection{Synthesis and characterization of the nanosized $\mathrm{TiO}_{2}$ particles}

$\mathrm{TiO}_{2}$ colloidal suspensions are usually made by hydrolysis of alkoxide precursors in an aqueous acidic environment. In this work, it was prepared from the controlled hydrolysis of titanium (IV) isopropoxide (TIP) by following procedures in the literature [36].

\subsubsection{Transmission electron micrographs}

The transmission electron micrographs of the TIP hydrolysate are shown in Fig. 1. It clearly shows the colloidal suspension is homogeneous and the particle size is around $10 \mathrm{~nm}$.

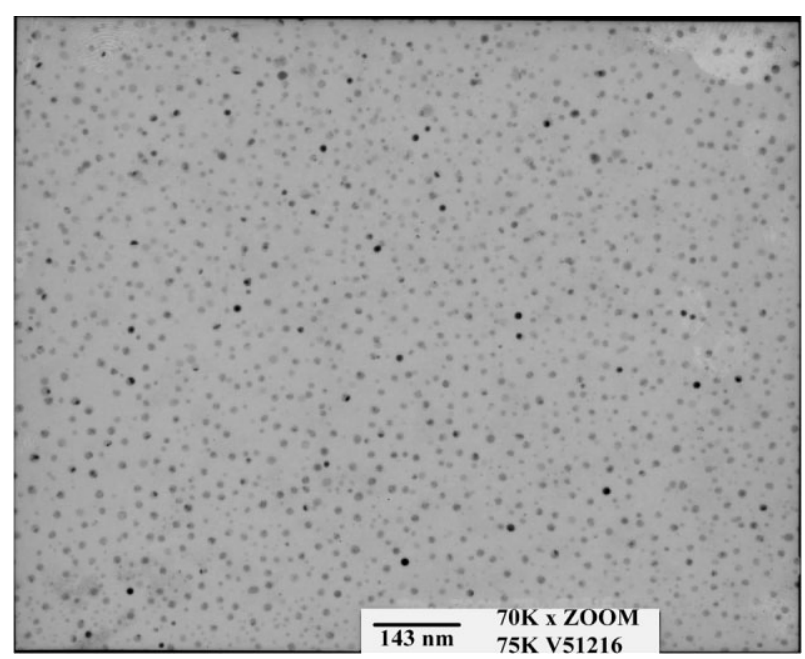

Figure 1. Transmission electron micrographs of $\mathrm{TiO}_{2} \mathrm{NPs}$ synthesized from the sol-gel method.

\subsubsection{Absorption spectra}

The UV spectrum shows the onset wavelength at $362 \mathrm{~nm}$ which is similar to that shown in [36]. This is evident for the formation of nanosized $\mathrm{TiO}_{2}$ colloids. Since the reaction rate for the hydrolysis of TIP is quite fast, TIP was diluted with 1-propanol prior to the reaction. A white precipitate was formed spontaneously at room temperature due to hydrolysis by the moisture in the air. For controlling the reaction rate, the sol-gel process was carried out at $4^{\circ} \mathrm{C}$ in an ice bath. The resultant product was transparent and colorless. To increase the yield, parameters which will affect the extent of hydrolysis and condensation reaction were studied. Increasing the temperature from 30 to $70^{\circ} \mathrm{C}$ and the duration up to $8 \mathrm{~h}$, it was found that $50^{\circ} \mathrm{C}$ and an aging period of $7 \mathrm{~h}$ were the most favorable conditions for the nanoparticle preparation. The condition chosen was assayed by measuring the absorbance at $340 \mathrm{~nm}$. If there is red-shift for the onset wavelength $(362 \mathrm{~nm})$ of the $\mathrm{TiO}_{2} \mathrm{NPs}$, the absorbance at $340 \mathrm{~nm}$ will increase. A constant absorbance at $340 \mathrm{~nm}$ was recognized as accomplishment of the TIP hydrolysis. In this way, the prepared nanoparticles could be stable for more than 6 months. To produce a higher concentration of the product, the colloidal solution $(100 \mathrm{~mL}$ ) was concentrated under vacuum to remove isopropanol. The final volume was $1 \mathrm{~mL}$, and the resulting concentration was around $40 \% \mathrm{w} / \mathrm{v}$.

\subsection{Column preparation}

PEG 8000 was added to the $\mathrm{TiO}_{2}$ colloidal $(40 \% \mathrm{w} / \mathrm{v})$ to avoid aggregation of the nanoparticles before introducing into the column [37]. The $\mathrm{p} /$ for sol-gel is defined as the $\mathrm{pH}$ where the zeta-potential is 0 [38]. The $\mathrm{pl}$ represents the point where electrostatic repulsion forces between colloidal particles are weakest, and, in most cases, the dispersion is most likely to aggregate [39]. To obtain and maintain a stable sol, peptization must generally be performed at a condition several $\mathrm{pH}$ units above or below the $\mathrm{pl}$.

\subsection{Characterization of the coated column}

\subsubsection{SEM picture of the coated capillary column}

The size and morphology of the nanoparticles after introduced into the column was also determined with scanning electron microscope (SEM). For the sake of getting a thicker film thickness of the coated $\mathrm{TiO}_{2} \mathrm{NPs}$, the column was initially prepared by one repetition coating procedures in Section 2.4. In other words, two condensation processes were carried out. Figure $2 \mathrm{~A}$ indicates the cross section of the prepared column. It is evident that the inner surface of the capillary $(50 \mu \mathrm{m}$ ID) was covered by $\mathrm{TiO}_{2}$ NPs. The coverage was nearly extended to the center of the column. Figure $2 \mathrm{~B}$ is the magnification of the 
(A)

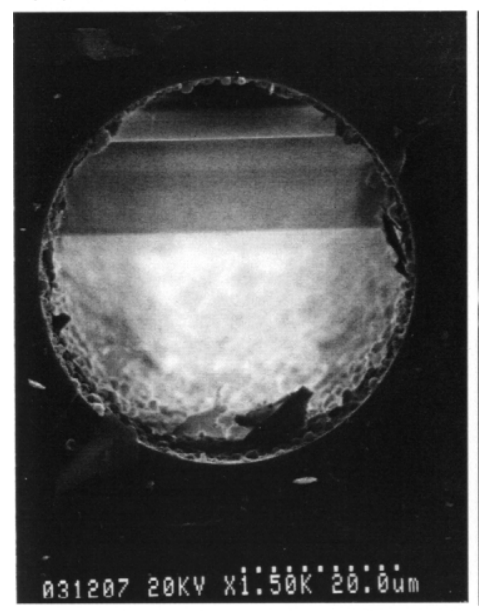

(B)

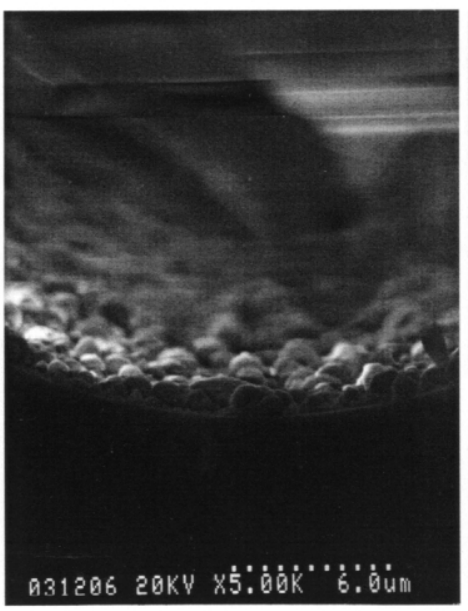

(C)

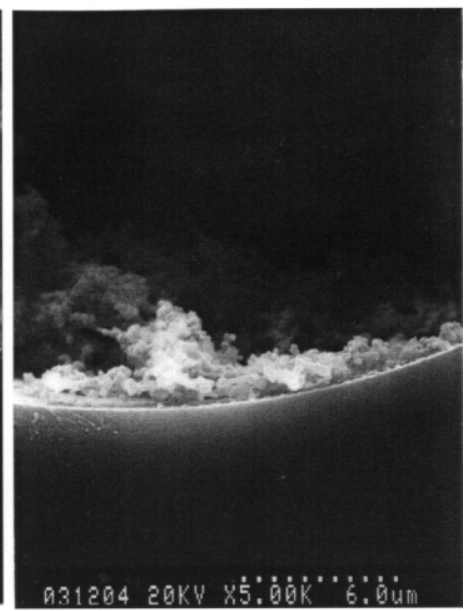

Figure 2. Scanning electron micrographs of $\mathrm{TiO}_{2} \mathrm{NPs}$-coated column. (A) Cross section of the column prepared by two-cycle coating procedures. (B) Edge of the column prepared by two-cycle coating procedures. $(\mathrm{C})$ Edge of the column prepared by a single coating procedure.

portion in Fig. 2A. It has been shown that $\mathrm{TiO}_{2} \mathrm{NPs}$ were tightly bonded onto the capillary column but the size of the microspheres is in the range from 10 to 100 . Two condensation reactions might result in more aggregation of the nanoparticles. For comparison, only one condensation process was also carried out. Figure $2 \mathrm{C}$ shows the morphology of the resultant column. The nanoparticle size is distinctly smaller than that by one-repetition procedure (Fig. 2B).

\subsubsection{Effect of buffer composition on the EOF}

As shown in Fig. 3B, the buffer composition has a pronounced effect on the EOF of the coated capillary but it was not the case for bare fused silica (Fig. 3A). Here curves a, b, c designate phosphate buffer $(\mathrm{pH} 2-10)$, formate ( $\mathrm{pH} 2-5) /$ Tris ( $\mathrm{pH} \mathrm{5-10),} \mathrm{and} \mathrm{glutamate} \mathrm{buffer}(\mathrm{pH} 4-$ 10), respectively. For a $\mathrm{TiO}_{2} \mathrm{NPs}$-coated column, a reversal EOF was found at $\mathrm{pH}$ below 5 in the formate buffer. $\mathrm{A}$ positive charge on the surface of the column was indicated while at $\mathrm{pH}$ above 5, the direction of the EOF changed from anode to cathode. No signal could be found at $\mathrm{pH}$ around 5 regardless the marker was injected from the positive end or the negative end. It can be concluded that the $\mathrm{pH}$ might be exactly the $\mathrm{p} /$ of the coated material. The assumption was corresponding to that reported by Dobson et al. [40].

According to data shown in [35], the oxygen monocoordinated titanium, $\mathrm{pK}_{1}$ for $>\mathrm{Ti}_{-} \mathrm{OH}_{2}{ }^{+} \rightarrow>\mathrm{Ti}-\mathrm{OH}+\mathrm{H}^{+}$ is $2.60, \mathrm{pK}_{2}$ for $>\mathrm{Ti}-\mathrm{OH} \rightarrow>\mathrm{Ti}-\mathrm{O}^{-}+\mathrm{H}^{+}$is 9.00 while for oxygen di-coordinated titanium, the $\mathrm{pK}$ value for
$>\mathrm{Ti}_{2}=\mathrm{OH} \rightarrow>\mathrm{Ti}_{2}=\mathrm{O}^{-}+\mathrm{H}^{+}$is 5.50 . It can be seen when the acidity of the medium is less than $\mathrm{pH} 4$, the bridging group $>\mathrm{Ti}_{2} \mathrm{OH}$ was fully in the molecular form. The surface charge of the column mainly stemmed from the species of $>\mathrm{TiOH}_{2}{ }^{+}$. In this case, an EOF might be reversal. At $\mathrm{pH}$ over the range from 4 to 7 , the terminal group on the coated material is $>\mathrm{TiOH}$. The surface charge might originate from the dissociation of the bridging group $>\mathrm{Ti}_{2} \mathrm{OH}$ but at $\mathrm{pH} 4-5.5$, only a little current was found. Much less surface charge is probably the reason, since its $\mathrm{pK}$ value is 5.50. At $\mathrm{pH}$ above 6, anodic EOF was switched into cathodic EOF due to the presence of highly dissociated $>\mathrm{Ti}_{2} \mathrm{OH}$. A buffer region was observed at $\mathrm{pH}$ around 9. This corresponds to the $\mathrm{p} K_{2}$ value of the terminal $>\mathrm{TiOH}$ group.

By changing the buffer composition into phosphate or glutamate buffer, only cathodic EOF was observed and no EOF reversal was indicated in the acidic solution. Phosphate ions are known to adsorb strongly to most metal oxides. It has been shown that phosphate ion binds to $\mathrm{TiO}_{2} \mathrm{NPs}$ as a bidentate surface species [41]. This resulted in a negative surface. The $\mathrm{pK}_{\mathrm{a}}$ values for $\mathrm{H}_{3} \mathrm{PO}_{4}$ are 2.14, 7.19, and 12.30. As can be seen in Fig. 3B, two buffer regions were indicated. But the dissociation constants of the adsorbed phosphoric acid exhibited somewhat different values from those of the free phosphoric acid. The estimated $\mathrm{p} K_{\mathrm{a} 1}$ is 2.82 and $\mathrm{p} K_{\mathrm{a} 2}$ is 7.71 .

Glutamic acid has two carboxylic acids and one amino group. The $p K_{\mathrm{a}}$ values are 2.10, 4.04, and 9.47. Surfacebinding properties of carboxylic groups on nanoparticulate $\mathrm{TiO}_{2}$ surface in hexanol has been studied by Weng et 

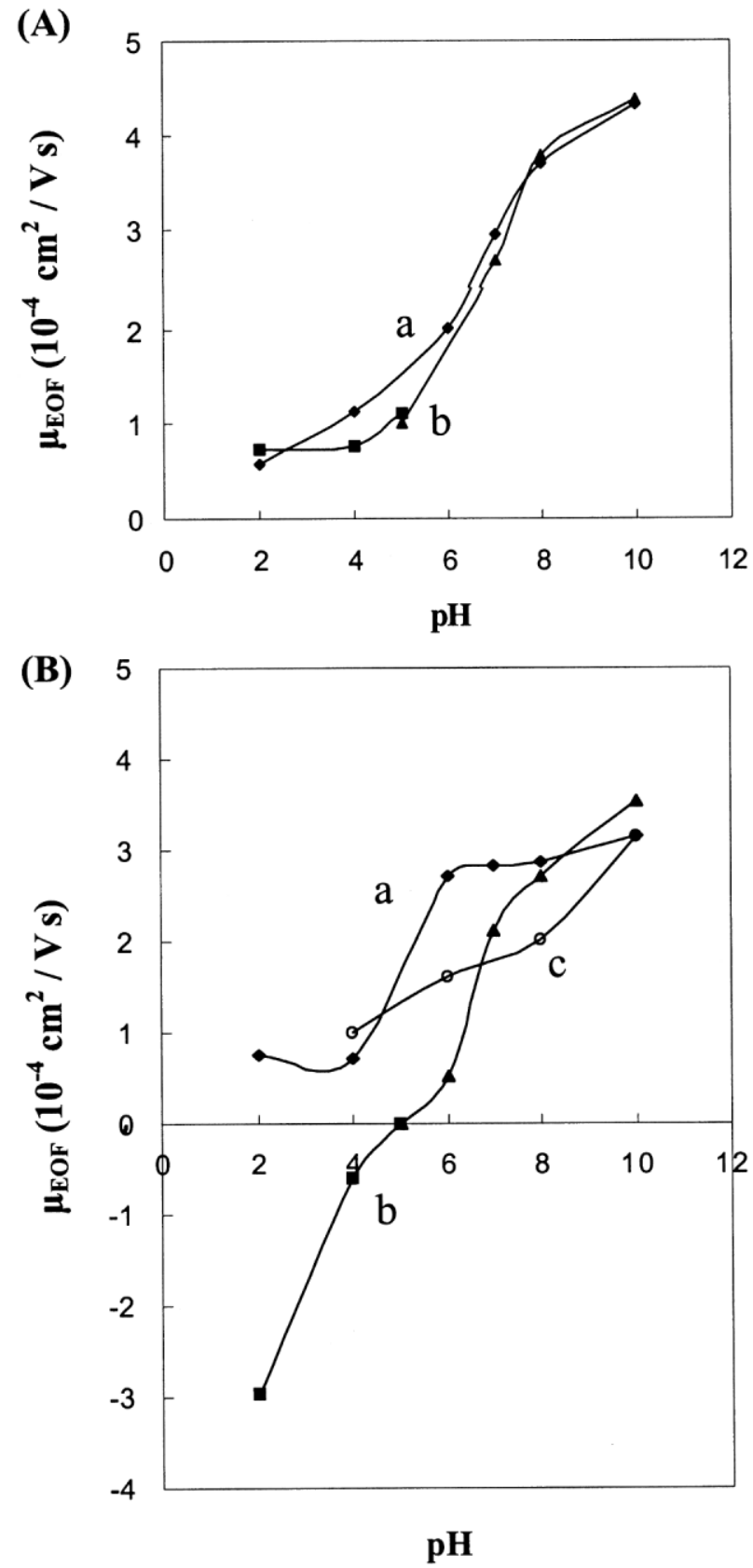

Figure 3. Effect of buffer $\mathrm{pH}$ and buffer composition on the EOF. Column dimension, 70 (50) $\mathrm{cm} \times 50 \mu \mathrm{m} \mathrm{ID}$; injection, hydrodynamic method $(10 \mathrm{~cm}, 2 \mathrm{~s})$; marker, benzyl alcohol; voltage, $+15 \mathrm{kV}$; detection, $214 \mathrm{~nm}$. (A) Bare fused-silica column: (a) phosphate buffer (40 mm) and (b) formate/Tris buffer (40 mM). (B) $\mathrm{TiO}_{2} \mathrm{NPs}$-coated column: (a) phosphate buffer $(40 \mathrm{~mm})$, (b) formate/Tris buffer (40 mM), and (c) glutamate buffer ( $40 \mathrm{~mm})$.

al. [42]. They proposed that at $\mathrm{pH} 3$, the main surface species on the nanoparticle is the ester-like linkage which constitutes about $63 \%$ of the total surface-binding molecules. The others are chelating and bridge forms as well as hydrogen bonding and anion forms. Although the surface-binding forms of glutamate on nanoparticulate $\mathrm{TiO}_{2}$ surface is not clear in our system, the cathodic EOF (Fig. 3B) indicates that a negative charge should be on the surface of $\mathrm{TiO}_{2} \mathrm{NPs}$. In other words, glutamate molecules are really bonded onto the $\mathrm{TiO}_{2}$ surface. Due to less variation among the $\mathrm{pK}_{\mathrm{a}}$ values compared with phosphoric acid, a smooth curve was found for the plotting of EOF versus $\mathrm{pH}$ (Fig. 3B).

\subsubsection{Effect of buffer concentration on EOF}

At a phosphate concentration of $5 \mathrm{~mm}$, the EOF was $1.5 \times 10^{-4} \mathrm{~cm}^{2} \mathrm{~N} \times \mathrm{s}$. The dependence of EOF on phosphate concentration in the range from 10 to $50 \mathrm{~mm}$ was found to be nearly constant, $3 \times 10^{-4} \mathrm{~cm}^{2} / \mathrm{V} \times \mathrm{s}$. The result indicated that $10 \mathrm{~mm}$ phosphate was enough for the coverage of the $\mathrm{TiO}_{2}$ surface.

\subsection{CEC separation of peptides}

Here angiotensin-type peptides, Ang-ST, Ang-I, and AngII, were chosen as the model compounds.

\subsubsection{Separation in formate/Tris buffer}

At acidic condition of the formate buffer $(\mathrm{pH} 2,40 \mathrm{~mm})$, the EOF is reversal. The peptides carry the positive charge which migrated in the counter direction with the EOF. We can detect it in the cathode. This means that the mobility of peptides is greater than that of EOF. The elution order was Ang-I > Ang-ST > Ang-II (Figs. 4a-c). It was distinct at highly acidic condition $(\mathrm{pH} 2)$, and can be explained by the relative mobility shown in Table 1. Longer retention time was indicated for $\mathrm{TiO}_{2} \mathrm{NPs}$ column by comparison with that of the bare fused-silica column (Fig. 4), but no significant difference for the retention time on columns prepared via one- or two-cycle condensation processes. Only broadening and peak tailing were found for the latter treatment. No benefit was found for the repetition coating procedures. Hence, one condensation process was recommended for column preparation.

As stated before at formate/Tris buffer, the surface charge of the $\mathrm{TiO}_{2} \mathrm{NPs}$ is positive at $\mathrm{pH}$ below 5 , while it carries negative charge at $\mathrm{pH}$ above 5 . By further considering the $\mathrm{p} /$ values of these analytes, electrostatic attraction is responsible for the solute-bonded phase interaction at $5<\mathrm{pH}<8$, while repulsive force was essential at the other outermost $\mathrm{pH}$. Moreover, Ang-ST is the $N$-methylated sarcosine derivative of Ang-II. It is not easy to coordinate with the titanium ion. So it was eluted the earliest. 
Table 1. Net charge and relative mobility of the analytes

\begin{tabular}{lllllll}
\hline Analyte & \multicolumn{4}{l}{ Relative mobility $\left(\times 10^{-2}\right)^{\mathrm{a})}(\text { net charge })^{\mathrm{b})}$} & & \\
\cline { 2 - 7 } & $\mathrm{pH} 2$ & $\mathrm{pH} 4$ & $\mathrm{pH} \mathrm{6}$ & $\mathrm{pH} \mathrm{7}$ & $\mathrm{pH} \mathrm{8}$ & $\mathrm{pH} \mathrm{10}$ \\
\hline Ang-I $\left(M_{\mathrm{r}}\right.$ 1296.49; $\left.\mathrm{pl} 7.91\right)$ & $3.09(3.67)$ & $2.04(2.42)$ & $0.85(1.01)$ & $0.15(0.18)$ & $0.00(-0.01)$ & $-0.98(-1.17)$ \\
Ang-II $(1046.19 ; 7.76)$ & $2.59(2.67)$ & $1.39(1.43)$ & $0.49(0.51)$ & $0.09(0.09)$ & $-0.02(-0.02)$ & $-1.14(-1.17)$ \\
Ang-ST $(956.1 ; 9.85)$ & $2.77(2.69)$ & $2.07(2.01)$ & $1.55(1.50)$ & $1.12(1.09)$ & $1.01(0.98)$ & $-0.17(-0.17)$ \\
\hline
\end{tabular}

a) Relative mobility was calculated from the Offord's equation: $\mu_{\mathrm{rel}}=\mathrm{charge} / M_{\mathrm{r}}^{2 / 3}$.

b) http://www.embl-heidelberg.de/cgi/pi-wrapper.pl
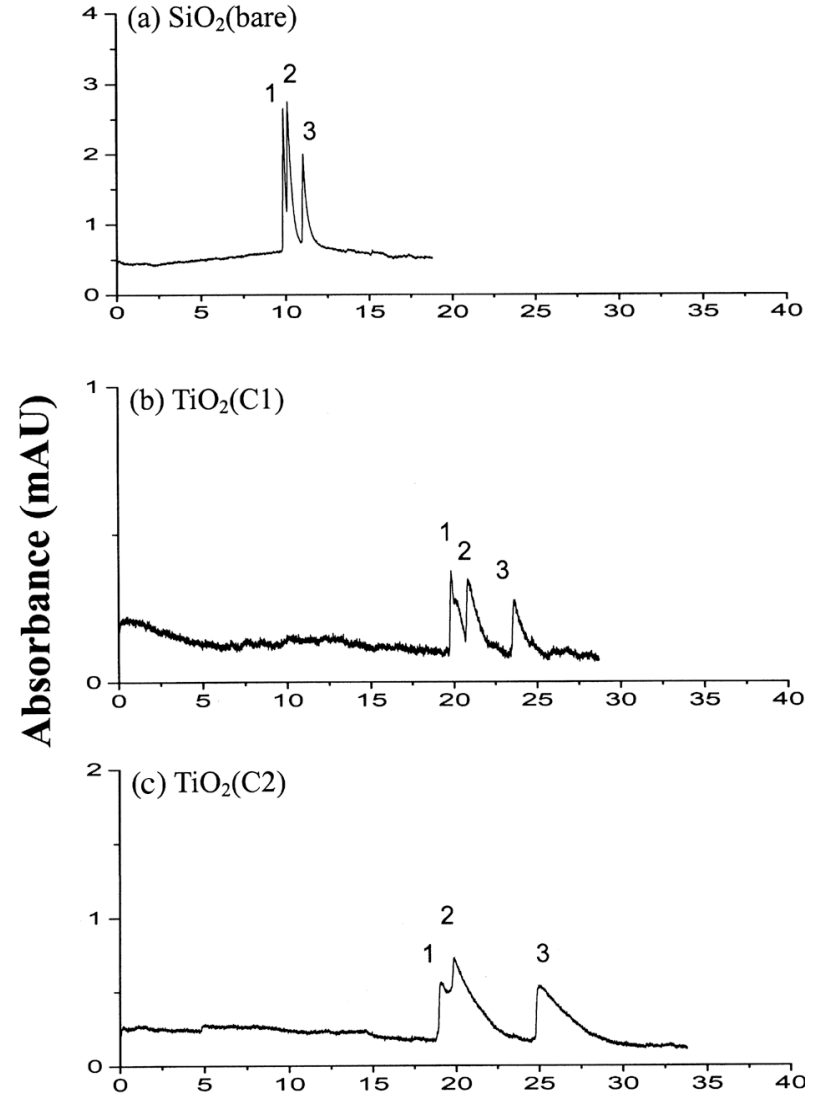

Retention time (min)

Figure 4. Film thickness of the $\mathrm{TiO}_{2} \mathrm{NPs}$ on the separation efficiency. Column dimension, 70 (50) $\mathrm{cm} \times 50 \mu \mathrm{m} \mathrm{ID}$; sample concentration, $250 \mu \mathrm{g} / \mathrm{mL}$ each; injection, $5 \mathrm{kV}$ for $2 \mathrm{~s}$; mobile phase, formate buffer $(\mathrm{pH} 2,40 \mathrm{~mm})$; voltage, $+15 \mathrm{kV}$; detection at $214 \mathrm{~nm}$. Peak identification: (1) Ang-I, (2) Ang-ST, and (3) Ang-II. (a) Bare fused silica. (b) $\mathrm{TiO}_{2} \mathrm{NPs}$ coated column (one-cycle coating).

(c) $\mathrm{TiO}_{2}$ NPs coated column (two-cycle coating).

Ang-I and Ang-II have aspartic acid in the $N$-terminal. A stable five-membered chelating ring with the titanyl ion would form. Because Ang-I has more amino acid residues than Ang-II, greater steric hindrance for the complexation with the $\mathrm{TiO}_{2} \mathrm{NPs}$ might result in less affinity than Ang-II. Therefore, the elution order is Ang-ST $>$ Ang-I $>$ Ang-II. At $\mathrm{pH}$ below 6 , a good separation was demonstrated (Fig. 5) but at $\mathrm{pH}$ above 7, the extent of ionization of both peptides and the surface negative charge of $\mathrm{TiO}_{2} \mathrm{NPS}$ increased. Charge repulsion increase resulted in lower affinity between them and eventually peak overlapping was observed.
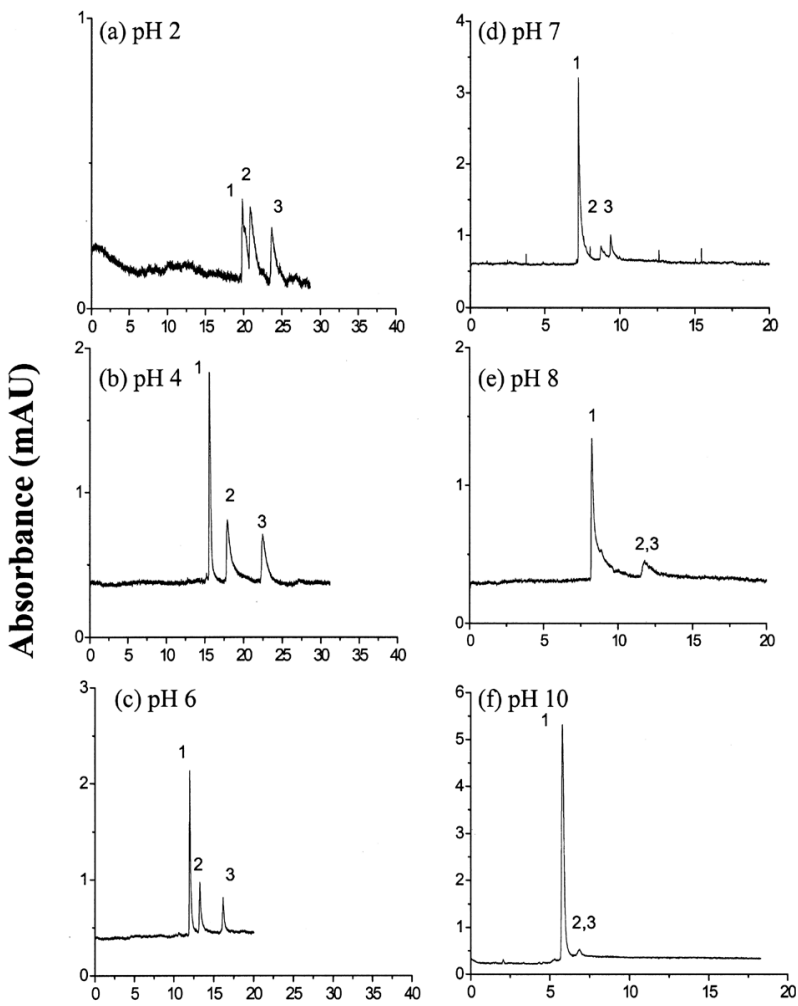

Retention time (min)

Figure 5. CEC separation of oligopeptides on $\mathrm{TiO}_{2} \mathrm{NPs}-$ coated column with formate/Tris buffer at various $\mathrm{pH}$ values. Conditions as in Fig. 4, except mobile phases $(40 \mathrm{~mm})$ are formate $(\mathrm{pH} 2-4)$ and Tris $(\mathrm{pH} \mathrm{6-10)}$. Peak identification: (1) Ang-ST, (2) Ang-I, and (3) Ang-II. 


\subsubsection{Separation in glutamate and phosphate buffer}

In the EOF measurement, it was found that both glutamate and phosphate buffer yield a greater negative charge layer attributable to the formation of titanium complex. The analyte was coeluted with the EOF. Faster elution than that in the formate/Tris buffer was indicated (Figs. 6, 7). Additionally, better efficiency was demonstrated with phosphate buffer. One more evidence was given that phosphate has a greater ability than glutamate to displace the analytes coordinated with the $\mathrm{TiO}_{2} \mathrm{NPs}$.

The influence of the phosphate buffer concentration (5, $10,20,40$, and $50 \mathrm{~mm}$ ) on separation was also examined. The higher the concentration, the greater peak height was indicated. On further increasing the concentration above $50 \mathrm{~mm}$, slight peak tailing was demonstrated. This might be due to slower EOF mobility and Joule heating.
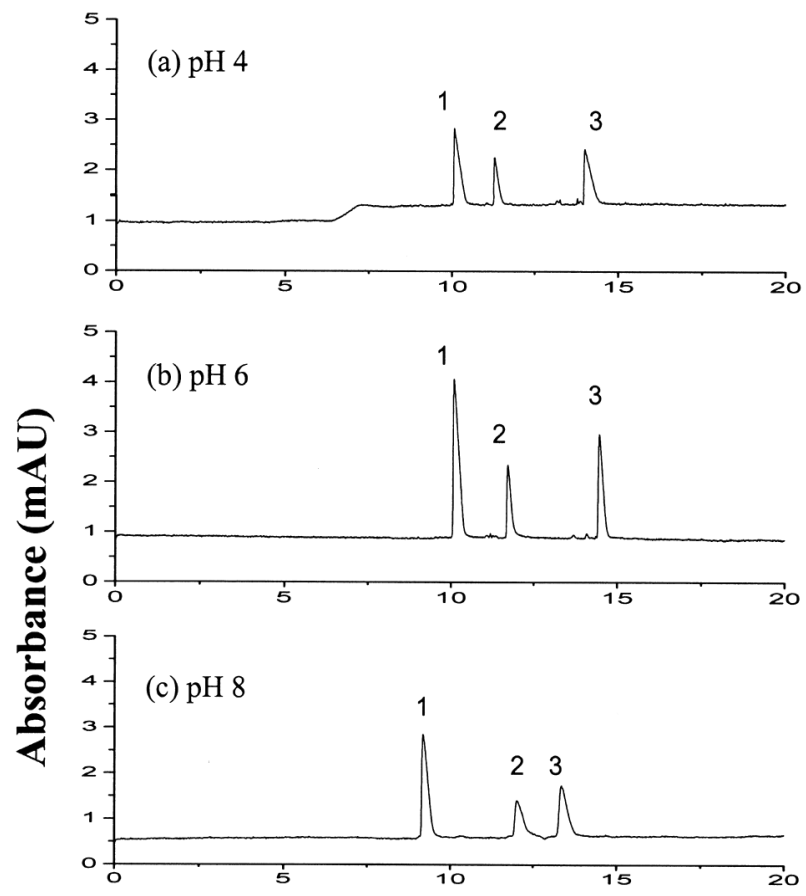

(d) $\mathrm{pH} 10$

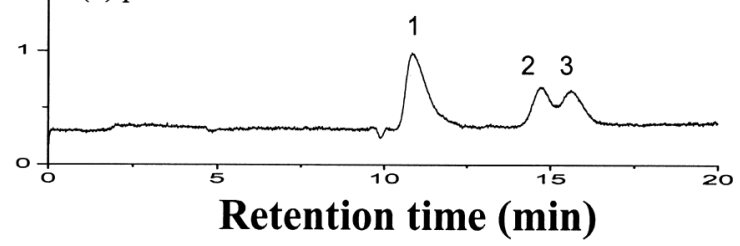

Figure 6. CEC separation of oligopeptides on $\mathrm{TiO}_{2} \mathrm{NPs}-$ coated column with glutamate buffer at various $\mathrm{pH}$ values. Conditions as in Fig. 4 except mobile phase: glutamate buffer (40 mm). Peak identification: (1) Ang-ST, (2) Ang-I, and (3) Ang-II.
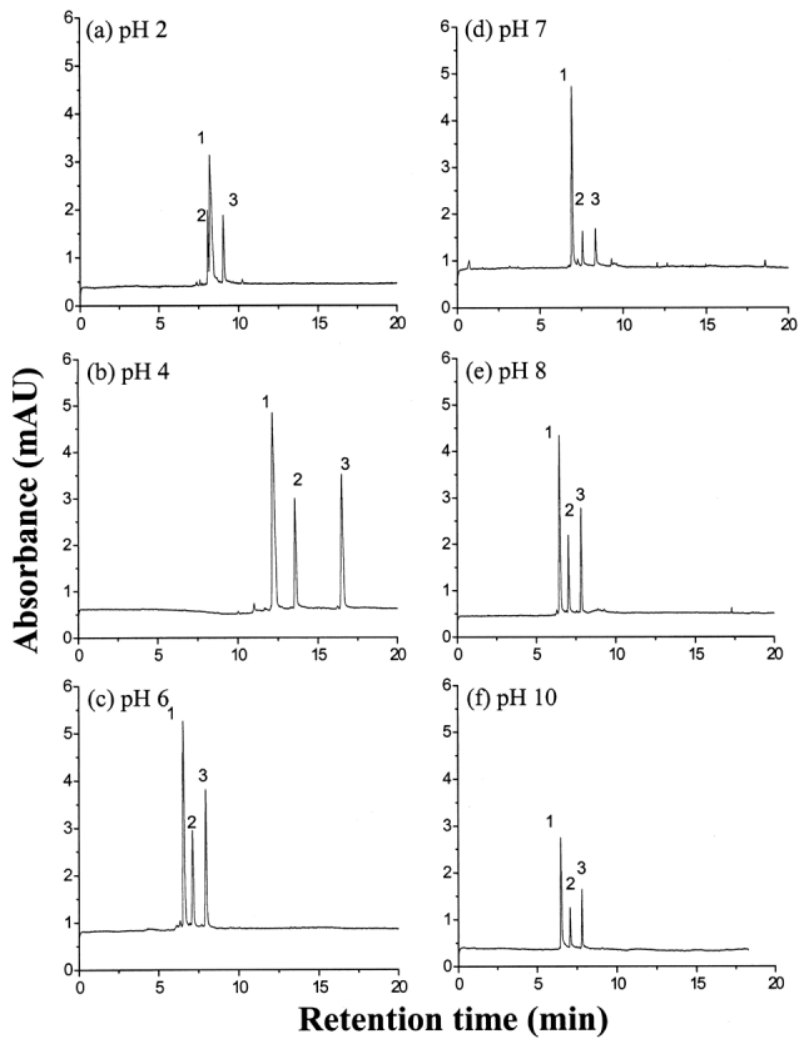

Figure 7. CEC separation of oligopeptides on $\mathrm{TiO}_{2} \mathrm{NPs}-$ coated column with phosphate buffer at various $\mathrm{pH}$ values. Conditions as in Fig. 4 except mobile phase: phosphate buffer (40 mm). Peak identification: (1) Ang-ST, (2) Ang-I, and (3) Ang-II.

\subsection{Separation mechanism}

The reactive groups in these peptides can be classified as follows: $\alpha$-carboxyl, $\gamma$-carboxyl, imidazole, $\alpha$-amino, $\varepsilon$-amino, methylamine, phenolic $\mathrm{OH}$, and guanidyl. By considering the active groups of the analyte and the surface charge of $\mathrm{TiO}_{2} \mathrm{NPs}$, ion-ion or ion-dipole, hydrogen bonding, and ligand exchange would be the main interaction force besides electrophoretic mobility difference. Since the coordination ability of the mobile phase with the $\mathrm{TiO}_{2} \mathrm{NPS}$ increased in the order: formate $<$ Tris $<$ glutamate $<$ phosphate, the highest peak height along with the least elution time was expected with phosphate buffer (Fig. 7 compared with Figs. 5, 6).

\subsection{Stability of the column}

The separation efficiency for phosphate buffer is summarized in Table 2. With phosphate buffer ( $\mathrm{pH} \mathrm{6,} 40 \mathrm{~mm}$ ) and applied voltage of $15 \mathrm{kV}$, a good separation of the angio- 
Table 2. Separation efficiency for the $\mathrm{TiO}_{2} \mathrm{NPs}$-coated column ${ }^{\mathrm{a}}$

\begin{tabular}{|c|c|c|c|c|c|c|c|c|c|c|c|c|c|c|c|c|c|c|}
\hline \multirow[t]{2}{*}{ Analyte } & \multicolumn{3}{|c|}{$\mathrm{pH} 2$} & \multicolumn{3}{|c|}{$\mathrm{pH} 4$} & \multicolumn{3}{|c|}{ pH 6} & \multicolumn{3}{|c|}{ pH 7} & \multicolumn{3}{|c|}{ pH 8} & \multicolumn{3}{|c|}{ pH 10} \\
\hline & $t_{R}, \min$ & $\mathrm{N}, / \mathrm{m}^{\mathrm{b})}$ & $R_{\mathrm{s}}^{\mathrm{c})}$ & $t_{R}, \min$ & $\mathrm{N}, / \mathrm{m}$ & $R_{\mathrm{s}}$ & $t_{R}, \min$ & $\mathrm{N}, / \mathrm{m}$ & $R_{\mathrm{s}}$ & $t_{R}, \min$ & $\mathrm{N}, / \mathrm{m}$ & $R_{\mathrm{s}}$ & $t_{R}, \min$ & $\mathrm{N}, / \mathrm{m}$ & $R_{\mathrm{s}}$ & $t_{R}, \min$ & $\mathrm{N}, / \mathrm{m}$ & $R_{\mathrm{s}}$ \\
\hline & 8 & 9 & 0.7 & & & - & & 0 & - & & & - & & & - & & 40000 & - \\
\hline Ang & 8.06 & 16000 & - & 13.58 & 83000 & 2.4 & 7. & 32000 & 3.5 & 7.5 & 52000 & 3.1 & $7 .($ & 56000 & 3.9 & 7.09 & 63000 & 0.4 \\
\hline Ang-II & 9.04 & 53000 & 2.9 & 16.48 & 81000 & 1.6 & 7.69 & 40000 & 4.0 & 8.37 & 40000 & 2.3 & 7.83 & 40000 & 2.5 & 7.83 & 94000 & 3.8 \\
\hline
\end{tabular}

a) $\mathrm{TiO}_{2}$ NPs-coated column: $70(50) \mathrm{cm} \times 50 \mu \mathrm{m}$; injection: $5 \mathrm{kV}, 2 \mathrm{~s}$; voltage: $15 \mathrm{kV}$; mobile phase: phosphate buffer (40 mm); detection at $214 \mathrm{~nm}$

b) Theoretical plate: $N=5.54\left(t_{\mathrm{R}} / w_{1 / 2}\right)^{2}$, where $t_{\mathrm{R}}$ and $w_{1 / 2}$ represent the retention time and the peak width at half-maximum, respectively.

c) Resolution, $R_{\mathrm{s}}=2\left(t_{\mathrm{R} 2}-t_{\mathrm{R} 1}\right) /\left(W_{1}+W_{2}\right)$.

tensin-type peptides could be achieved with average theoretical plates of $3.1 \times 10^{4} / \mathrm{m}$. The RSD for the retention time (min) was $1.21 \%$ for Ang-ST, 1.51\% for Ang-I, and $1.43 \%$ for Ang-II based on five measurements between days. To assess the long-term stability of the column, the results from five consecutive injections were measured after the column had been used for longer than 1 month, namely, more than 100 injections have taken place. All RSD values were less than $3.00 \%$. In this work, the procedure for the column preparation is very simple and convenient. The nanoparticles were introduced into the capillary under a nitrogen flow of $100 \mathrm{~kg} / \mathrm{m} \times \mathrm{s}^{2}$ lasting for $10 \mathrm{~min}$. Therefore, it is easy to control the film thickness, which in turn is able to get highly reproducible column efficiency.

\section{Concluding remarks}

To our knowledge, this is the first attempt in CEC to use a simple way to prepare a titanium dioxide NPs-coated column. The covalent bonding was due to the condensation reaction directly with the silanol group on the inner wall of the fused-silica capillary. Dissimilar surface properties on the $\mathrm{TiO}_{2} \mathrm{NPs}$ were exhibited at formate/Tris, glutamate, and phosphate buffers. With angiotensin-type oligopeptides as model compounds, the separation performance indicated that the column could be highly promising for manipulation of the selectivity between solutes in CEC and other separation systems. Most of the stationary phases for the CEC separation of peptides or proteins are sol-gel/organic hybrid material irrespective the support is silica or titania [8, 9, 29-31, 33, 34]. Comparing the separation characteristics for a series of angiotensins on bare, diol-, and C-18-etched capillaries reported by Pesek et al. [29], the elution order is the same. But the column they used is made by the steps of etching, silanization, and organic moiety attaching. In this work, only a $\mathrm{TiO}_{2} \mathrm{NPs}$-coated column and no organic moiety attached was used for the separation of angiotensins. By considering the active groups of the analytes and the surface charge of $\mathrm{TiO}_{2} \mathrm{NPs}$, ion-ion or ion-dipole, hydrogen bonding, and ligand exchange would be the main interaction force beside electrophoretic mobility difference. The separation of proteins will be described elsewhere.

The authors thank the National Science Council of Taiwan for financial support.

Received April 15, 2005

Revised August 3, 2005

Accepted August 3, 2005

\section{References}

[1] Kawahara, M., Nakamura, H., Nakajima, T., Anal. Sci. 1989, $5,763-764$

[2] Trüdinger, U., Müller, G., Unger, K. K., J. Chromatogr. 1990, 535, 111-125.

[3] Pesek, J. J., Matyska, M. T., Ramakriishnan, J., Chromatographia 1997, 44, 538-544.

[4] Tani, K., Sumizawa, T., Watanabe, M., Tachibana, M., Koizumi, H., Kiba, T., Chromatographia 2002, 55, 33-37.

[5] Jiang, Z. T., Zuo, Y. M., Anal. Chem. 2001, 73, 686-688.

[6] Pinkse, M. W. H., Uitto, P. M., Hilhorst, M. J., Ooms, B., Heck, A. J. R., Anal. Chem. 2004, 76, 3935-3943.

[7] Sano, A., Nakamura, H., Anal. Sci. 2004, 20, 861-864.

[8] Tsai, P., Wu, C. T., Lee, C. S., J. Chromatogr. B 1994, 657, 285-290.

[9] Fujimoto, C., Electrophoresis 2002, 23, 2929-2937.

[10] Simal-Gándara, J., Crit. Rev. Anal. Chem. 2004, 34, 85-94.

[11] Stol, R., Poppe, H., Kok, W. Th., Anal. Chem. 2003, 75, 5246-5253.

[12] Piraino, S. M., Dorsey, J. G., Anal. Chem. 2003, 75, 42924296.

[13] Chen, T. S., Liu, C. Y., Electrophoresis 2001, 22, 2606-2615.

[14] Bedair, M., El Rassi, Z., Electrophoresis 2004, 25, 41104119. 
[15] Hilder, E. F., Svec, F., Fréchet, J. M. J., J. Chromatogr. A 2004, 1044, 3-22.

[16] Chuang, S. C., Chang, C. Y., Liu, C. Y., J. Chromatogr. A 2004, 1044, 229-236.

[17] Huang, Y. C., Lin, C. C., Liu, C. Y., Electrophoresis 2004, 25, 554-561.

[18] Chen, G. J., Lee, N. M., Hu, C. C., Liu, C. Y., J. Chromatogr. A 1995, 699, 343-351.

[19] Liu, C. Y., Chen, W. H., J. Chromatogr. A 1998, 815, 251263.

[20] Liu, C. Y., Ho, Y. W., Pai, Y. F., J. Chromatogr. A 2000, 897, 383-392.

[21] Shiue, C. C., Lin, S. Y., Liu, C. Y., J. Chin. Chem. Soc. 2001, 48, 1029-1034.

[22] Pai, Y. F., Liu, C. Y., J. Chromatogr. A 2002, 982, 293-301.

[23] Lin, S. Y., Liu, C. Y., Electrophoresis 2003, 24, 2973-2982.

[24] Guihen, E., Glennon, J. D., J. Chromatogr. A 2004, 1044, 6781.

[25] Neiman, B., Grushka, E., Lev, O., Anal. Chem. 2001, 73, 5220-5227.

[26] O’Mahony, T., Owens, V. P., Murrihy, J. P., Guihen, E., Holmes, J. D., Glennon, J. D., J. Chromatogr. A 2003, 1004, 181-193.

[27] Yang, L., Guihen, E., Holmes, J. D., Loughran, M., O’Sullivan, G. P., Glennon, J. D., Anal. Chem. 2005, 77, 1840-1846.

[28] Viberg, P., Jornten-Karlsson, M., Petersson, P., Spégel, P., Nilsson, S., Anal. Chem. 2002, 74, 4595-4601.
[29] Pesek, J. J., Matyska, M. T., Mauskar, L., J. Chromatogr. A 1997, 763, 307-314.

[30] Pesek, J. J., Matyska, M. T., Dawson, G. B., Chen, J. I. C., Boysen, R. I., Hearn, M. T. W., Anal. Chem. 2004, 76, 23-30.

[31] Matyska, M. T., Pesek, J. J., J. Chromatogr. A 2005, 1079, 366-371.

[32] Unger, K. K., Hennessy, T. P., Huber, M., Hearn, M. T. W., Walhagen, K., Anal. Chem. 2002, 74, 200A-207A.

[33] Malik, A., Electrophoresis 2002, 23, 3973-3992.

[34] Li, W., Fries, D. P., Malik, A., J. Chromatogr. A 2004, 1044, 23-52.

[35] Oliva, F. Y., Avalle, L. B., Cámara, O. R., de Pauli, C. P., J. Colloid Interface Sci. 2003, 261, 299-311.

[36] Kamat, P. V., Flumiani, M., Dawson, A., Colloids Surf. A 2002, 202, 269-279.

[37] Baraton, M. I., Synthesis, Functionalization and Surface Treatment of Nanoparticles, American Scientific Publishers, Stevenson Ranch, CA, 2003, Chapter 8.

[38] Venz, P. A., Kloprogge, J. T., Frost, R. L., Langmuir 2000, 16, 4962-4968.

[39] Venz, P. A., Frost, R. L., Kloprogge, J. T., J. Non-Cryst. Solids 2000, 276, 95-112.

[40] Dobson, K. D., Connor, P. A., McQuillan, A. J., Langmuir 1997, 13, 2614-2616.

[41] Connor, P. A., McQuillan, A. J., Langmuir 1999, 15, 29162921.

[42] Weng, Y. X., Li, L., Liu, Y., Wang, L., Yang, G. Z., J. Phys. Chem. B 2003, 107, 4356-4363. 